\title{
Evaluating model performance of an ensemble-based chemical data assimilation system during INTEX-B field mission
}

\author{
A. F. Arellano Jr. ${ }^{1}$, K. Raeder ${ }^{2}$, J. L. Anderson ${ }^{2}$, P. G. Hess ${ }^{1}$, L. K. Emmons ${ }^{1}$, D. P. Edwards ${ }^{1}$, G. G. Pfister ${ }^{1}$, \\ T. L. Campos ${ }^{1}$, and G. W. Sachse ${ }^{3}$ \\ ${ }^{1}$ Atmospheric Chemistry Division, Earth and Sun Systems Laboratory, National Center for Atmospheric Research, PO Box \\ 3000, Boulder, Colorado 80307-3000, USA \\ ${ }^{2}$ Institute for Mathematics Applied to Geosciences, Computational and Information Systems Laboratory, National Center for \\ Atmospheric Research, PO Box 3000, Boulder, Colorado, 80307-3000, USA \\ ${ }^{3}$ Chemistry and Dynamics Branch, NASA Langley Research Center, Hampton, Virginia, 23681-2199, USA
}

Received: 1 June 2007 - Published in Atmos. Chem. Phys. Discuss.: 5 July 2007

Revised: 30 October 2007 - Accepted: 31 October 2007 - Published: 16 November 2007

\begin{abstract}
We present a global chemical data assimilation system using a global atmosphere model, the Community Atmosphere Model (CAM3) with simplified chemistry and the Data Assimilation Research Testbed (DART) assimilation package. DART is a community software facility for assimilation studies using the ensemble Kalman filter approach. Here, we apply the assimilation system to constrain global tropospheric carbon monoxide $(\mathrm{CO})$ by assimilating meteorological observations of temperature and horizontal wind velocity and satellite $\mathrm{CO}$ retrievals from the Measurement of Pollution in the Troposphere (MOPITT) satellite instrument. We verify the system performance using independent $\mathrm{CO}$ observations taken on board the NSF/NCAR C-130 and NASA DC-8 aircrafts during the April 2006 part of the Intercontinental Chemical Transport Experiment (INTEX-B). Our evaluations show that MOPITT data assimilation provides significant improvements in terms of capturing the observed $\mathrm{CO}$ variability relative to no MOPITT assimilation (i.e. the correlation improves from 0.62 to 0.71 , significant at $99 \%$ confidence). The assimilation provides evidence of median CO loading of about $150 \mathrm{ppbv}$ at $700 \mathrm{hPa}$ over the NE Pacific during April 2006. This is marginally higher than the modeled CO with no MOPITT assimilation $(\sim 140 \mathrm{ppbv})$. Our ensemble-based estimates of model uncertainty also show model overprediction over the source region (i.e. China) and underprediction over the NE Pacific, suggesting model errors that cannot be readily explained by emissions alone. These results have important implications for improving regional chemical forecasts and for inverse modeling of $\mathrm{CO}$ sources and further demonstrate the utility of the assimilation system in comparing non-coincident measurements, e.g. comparing satellite retrievals of $\mathrm{CO}$ with in-situ aircraft measurements.
\end{abstract}

Correspondence to: A. F. Arellano Jr.

(arellano@ucar.edu)

\section{Introduction}

The availability of near-global and long-term measurements of tropospheric chemical constituents from space offers an opportunity to better understand changes in tropospheric composition through the integration of measurements with predictions from global chemical transport models. Central to this integration is a chemical data assimilation system that is reasonably efficient and flexible in assimilating measurements of various scales and of various chemical species. Such a system is useful as a tool in providing initial conditions for chemical weather forecasts, which are important in regional to global air quality and field missions (e.g. Chai et al., 2006). Here, the term chemical weather is analogous to meteorological weather and is described by Lawrence et al. (2005) as the local to global distribution of important trace gas and aerosols and their associated short-term variability. Such a system is also useful in building a framework for model system diagnosis and process evaluation (e.g. Lary, 1999; Rasch et al., 2001), as well as in conducting retrospective analysis of chemically and radiatively important trace gases and aerosols (e.g. Dethof and Holm, 2004; Stajner et al., 2001; Juckes and Lawrence, 2006 among others).

Chemical data assimilation systems extend from simple suboptimal techniques such as Newtonian relaxation (nudging, e.g. Sekiyama and Shibata, 2005), optimal interpolation (OI, e.g. Levelt et al., 1998; Lamarque et al., 1999; Clerbaux et al. 2001; Collins et al., 2001), variations of suboptimal Kalman filtering (e.g. Khattatov et al., 2000; Menard et al., 2000; Lamarque et al., 2002; Lamarque et al., 2003; Auger and Tangborn, 2004), to more complex techniques such as four-dimensional variational methods (4D-var, e.g. Fisher and Lary, 1995; Elbern and Schmidt, 1999; Wang et al., 2001; Eskes et al., 2003; Engelen and McNally, 2005; Chai et al., 2006) and ensemble-based approaches (EnKF,

Published by Copernicus Publications on behalf of the European Geosciences Union. 
e.g., van loon et al., 2000; Hanea et al., 2004; Eben et al., 2005; Sandu et al., 2005). Incorporation of bias estimation and model parameter estimation in chemical data assimilation has also been applied in recent years (Elbern et al., 2000; Lamarque et al., 2004; Yudin et al., 2004) to enhance the fidelity of model forecasts and analyses.

Reports of improved performance using variational or ensemble-based data assimilation in global atmospheric models (Rabier, 2005; Houtekamer et al., 2005) and chemical transport models (Chai et al., 2006; Sandu et al., 2005) are encouraging. Such techniques are especially appealing to studies in global atmospheric constituent transport and chemistry where observations are available for a range of chemical species having observation operators of varying complexity. They also have the potential to provide conditional distributions of poorly-observed or unobserved model parameters, such as surface fluxes or emission rates (e.g. Rayner et al., 2005; Muller and Stavrakou, 2005; Peters et al., 2005; Frankenberg et al., 2006; Elbern et al., 2007) that are relevant to modeling transport and chemistry and in designing pollution control strategies. More recent collaborative efforts to include atmospheric chemical constituents such as $\mathrm{CO}_{2}, \mathrm{O}_{3}$ and $\mathrm{CO}$ in global prediction systems also show great potential for significant gains in meteorology, climate and chemistry (e.g. Engelen and McNally, 2005; McLaughlin et al., 2005).

We continue these efforts by applying an ensemble-based approach in assimilating both meteorological and chemical observations with a global atmospheric model. In particular, we present an ensemble-based chemical data assimilation system using a global atmospheric model, the Community Atmosphere Model (CAM3) with simplified chemistry, and an assimilation package, the Data Assimilation Research Testbed (DART) developed at the National Center for Atmospheric Research (NCAR). This system serves as an online global chemical transport model (GCTM) with observational constraints to both meteorological fields and trace gas distribution. For this reason, it potentially offers a consistent global representation of the dynamical and chemical state of the atmosphere with an opportunity for studies related to coupling of chemistry and meteorology. To our knowledge, this type of system is one of the first applications of EnKF in global chemical data assimilation. In this work, we demonstrate its utility to chemical weather forecasting. In particular, we apply the DART/CAM data assimilation system to better constrain the global distribution of $\mathrm{CO}$. We validate our results against independent observations from NASA's Intercontinental Chemical Transport Experiment B (INTEX-B) field mission conducted over the northern Pacific in Spring 2006 (http://www.espo.nasa.gov/intex-b). We show a significant improvement in modeling the $\mathrm{CO}$ distribution with assimilation of meteorological observations and $\mathrm{CO}$ retrievals from the Measurement of Pollution in the Troposphere (MOPITT) instrument on the Terra satellite. We also show that such constraints in $\mathrm{CO}$ distribution provides a structure of $\mathrm{CO}$ forecasts different from that derived from model simulations and forecast systems with no $\mathrm{CO}$ assimilation.

The outline of the paper is as follows. In Sect. 2, we present in detail the components of the global chemical data assimilation system being developed and applied specifically to $\mathrm{CO}$ data assimilation. We describe the assimilation experiments conducted for initial verification of the system in Sect. 3 followed by a presentation of results and verification with INTEX-B CO data in Sects. 4.1 to 4.2 and a discussion on several insights from the experiment results in Sects. 4.3 and 4.4. Further analysis on the assimilation diagnostics are presented in Sect. 4.5 followed by summary and conclusions in Sect. 5.

\section{Description of the chemical data assimilation system}

\subsection{Data Assimilation Research Testbed (DART)}

DART is a community assimilation software package being developed at the Data Assimilation Research Section (DAReS) of NCAR (http://www.image.ucar.edu/DAReS/ DART). Built under an ensemble Kalman filter (EnKF) assimilation framework, it provides a flexible and extensible environment for collaborative data assimilation research and application. Originally introduced by Evensen (1994), the underlying principle of an ensemble Kalman filter is to perform an ensemble of forecasts and analysis cycles or an ensemble of Kalman filters. The error statistics are approximated using a finite sample of model states as opposed to handling explicitly a large error covariance matrix. This has the advantage of reduced cost in propagating the error statistics relative to a Kalman filter. It is also simple to implement and flexible compared to variational assimilation approaches such as $4 \mathrm{D}-\mathrm{VAR}$, which requires the development of a tangent linear and an adjoint of the GCTM. Further details on the comparison of 4D-VAR and EnKF are discussed in Lorenc (2005).

In this particular application, we use the ensemble adjustment Kalman filter scheme (EAKF) introduced by Anderson (2001). The EAKF approach differs from other EnKF schemes (e.g. Houtekamer and Mitchell, 1998) in its deterministic analysis update, which ensures that both the ensemble posterior mean and the posterior error covariance as estimated by the ensemble are consistent with Kalman filtering theory. Based on Anderson (2001) and other variants of what is generally known as deterministic ensemble square root filters (EnSRF, Tippett et al., 2003), this type of assimilation scheme updates the prior ensemble to a new set of observations without the addition of stochastic noise.

In practice, the use of EAKF (and EnKF) in global chemical data assimilation requires some additional approximations in computing posterior means and covariances. The approximations are needed to minimize degeneracy in co- 
variance matrices, errors in sampling, and filter divergence, as a result of using limited ensemble sizes for computational expedience in such large systems. Our first approximation involves applying the filter locally and independently onto subsets of the model states. In particular, we use the filter on $\mathrm{CO}$ observations to only influence the model CO states. We also use the filter on temperature and wind velocity observations to only influence a subset of the model meteorological states that includes temperature, wind, surface pressure, specific humidity, cloud ice and cloud water. Our second approximation involves artificially inflating the covariance to account for model error, low bias and inaccuracies in sampling the prior covariance and mean by a small ensemble size (Anderson and Anderson, 1999). Such error causes the prior covariances to shrink at some point in the assimilation, ultimately causing filter divergence. Specifically, the ensemble is linearly inflated around its mean prior to the update, by increasing the deviations of each ensemble member about their ensemble mean with an inflation factor slightly larger than one. This covariance inflation retains the information of the ensemble mean and correlation structure between ensemble state variables. We use a constant inflation factor which is calculated empirically such that the ensemble mean rootmean-square error (RMSE) relative to observations is at its minimum. The values of the inflation factor we obtained for each assimilation cycle range from 1.1 to 1.4. There are however more advanced methods in dealing with covariance inflation, which are currently being developed and tested for future applications (e.g. Anderson, 2007b). In effect, these two approximations avoid degeneracy in sample covariances of small ensemble sizes. Our third approximation involves the use of covariance localization. This is also related to our first approximation, but here we use the localization to minimize the impact of spurious correlations between an observation and a state variable that are physically separated (Hamill et al., 2001; Anderson, 2007a). We multiply the sample covariance between the observation and the state variable by a distance dependent correlation function with local support. We use the fifth order piecewise rational function from Eq. (4.10) of Gaspari and Cohn (1999) for this application.

\subsection{Community Atmosphere Model (CAM3)}

We use the Community Atmosphere Model (CAM) version 3.1.1 as the model component of our chemical data assimilation system (CDAS). CAM3 is an atmospheric general circulation model (AGCM) developed as either a stand-alone AGCM or as an atmospheric component of the community climate system model, CCSM3 (see http://www.ccsm.ucar. edu/models/atm-cam for documentation, input datasets and model simulations). A full description of its physics and dynamical formulation is also given by Collins et al. (2006). We use CAM3 with the finite-volume (FV) dynamical core at a spatial resolution of $2^{\circ} \times 2.5^{\circ}$ horizontal and 26 vertical levels with a model top of about $4 \mathrm{hPa}$. We choose to use the FV dy- namical core as it exhibits certain numerical properties (e.g. conservative, less diffusive) favorable for tracer transport and chemistry studies (Rasch et al., 2006). A coupling of CAM with the Model for Ozone And Related chemical Tracers v4 (MOZART4) chemistry (or CAM-MZ4) has been developed for climate-chemistry studies (Lamarque et al., 2005).

For $\mathrm{CO}$ simulations, we treat $\mathrm{CO}$ as a tracer constituent in CAM3, by specifying the direct emissions (e.g. fossil-fuel, biofuel, biomass burning, biogenic) and indirect emissions (e.g. chemical oxidation of hydrocarbons) of $\mathrm{CO}$ and prescribing the sink of $\mathrm{CO}$ by fixing the distribution of $\mathrm{OH}$ radicals (e.g. Granier et al., 1999; Bey et al., 2001). This is appropriate due to the medium lifetime of $\mathrm{CO}$ (globally about 2 months) and the dominance of oxidation by $\mathrm{OH}$ as the $\mathrm{CO}$ sink. Both the $\mathrm{OH}$ fields and $\mathrm{CO}$ from chemical oxidation of hydrocarbons are taken from an archive of MOZART4 full chemistry simulation (Emmons et al., 2007 ${ }^{1}$ ). While it is envisaged that future $\mathrm{CAM} / \mathrm{CO}$ simulations will be performed using interactive chemistry (in anticipation of possible multispecies chemical data assimilation), this work reports model simulations using the "tagged-CO" scheme for the purpose of initial CDAS development.

\subsection{Initial ensembles}

Below, we describe our approach for generating our initial ensembles of model states. It is recognized that having a reasonable representation of the initial ensembles (both its mean and spread) appreciably aids in making a successful ensemble-based CDAS (e.g. Sandu et al., 2005). Albeit limited in scope, our approach is predicated on the assumption that the variability of the $\mathrm{CO}$ state is mostly due to the variability induced from atmospheric transport (Allen et al., 1996) and from the spatial and temporal variability in emissions (e.g. Logan, 1981; Novelli et al., 2003). We partition our approach to include the following pre-processing procedures: 1) create an initial ensemble of CAM meteorological state variables, 2) create a monthly ensemble of CO total emissions, and 3) create an ensemble of $\mathrm{CO}$ distributions consistent with our ensembles in meteorology and emissions. The choice of using an ensemble of meteorology and an ensemble of emissions within an online GCTM framework is directly tied to the need of an EnKF system to maintain the variability of CO states over the period of forecast and analysis cycles.

\subsubsection{Ensemble of meteorological state variables}

A 20-member ensemble of CAM initial conditions for 1 April 2006 is constructed using a 100-year climatological

\footnotetext{
${ }^{1}$ Emmons, L. K., Hess, P. G., Lamarque, J.-F., Fillmore, D., Granier, C., Kinnison, D., Laepple, T., Orlando, J., Pétron, G., Pfister, G., Tie, X., Tyndall, G., and Walters, S.: Sensitivity of chemical budgets to meteorology in MOZART-4, manuscript in preparation, 2007.
} 

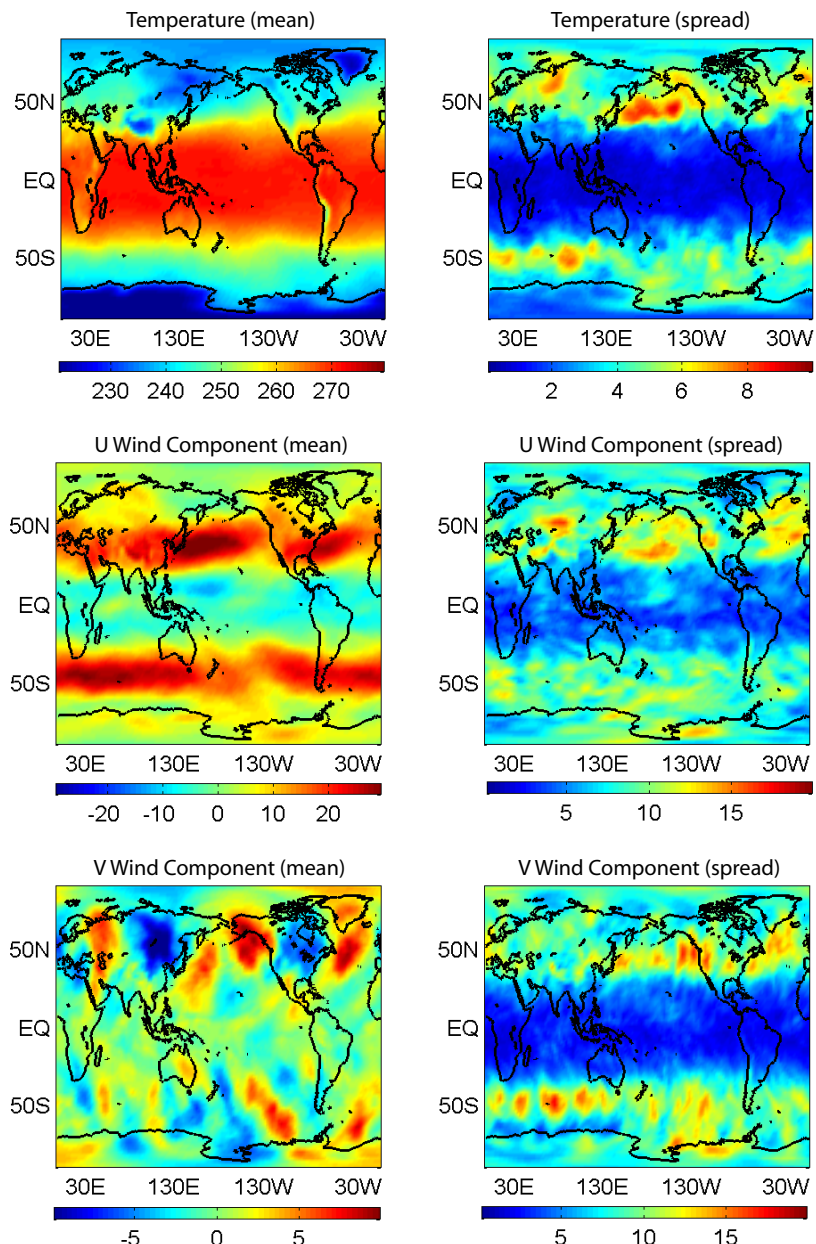

Fig. 1. Ensemble-mean (left panels) and ensemble-spread (right panels) of initial conditions for CAM3 temperature $(T)$ in $\mathrm{K}$, horizontal wind velocity components $U$ and $V$ in $\mathrm{m} / \mathrm{s}$ at $500 \mathrm{hPa}(1$ April 2006).

simulation of CAM. It is assumed here that each 1 April initial condition across the entire span of the climatological simulations is a realization of CAM meteorology for a climatological April and that the 100-year period spans the spread or variability of the majority of CAM state variables. A subset of these initial files is used as members of our ensemble of CAM initial conditions. Shown in Fig. 1 are ensemble means and ensemble spreads of CAM temperature and horizontal wind velocity state variables. They are calculated from the 20-member ensemble generated for CAM initial conditions. Here, the large spread is interpreted as a gross estimate of variability of the modeled initial states which is intended to be larger than typical uncertainties of modeled states.

\subsubsection{Ensemble of CO total emissions}

We based our estimates of uncertainty in $\mathrm{CO}$ emissions on recent inverse modeling results, as well as on recent
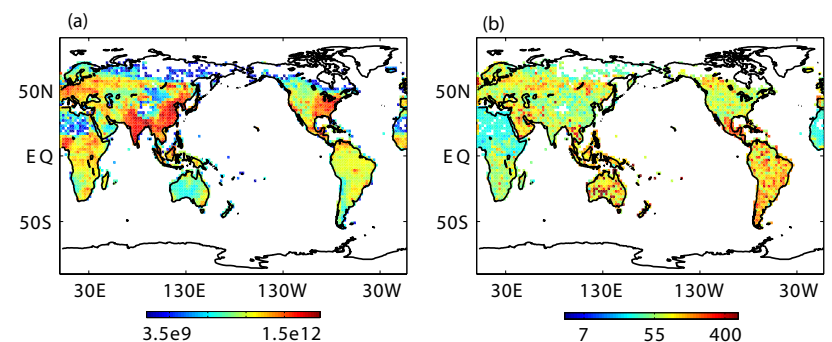

Fig. 2. Ensemble-spread of CAM3 total surface $\mathrm{CO}$ emissions for the month of April 2006 in molecules $/ \mathrm{cm}^{2} / \mathrm{s}$ (a), and in percentage $\%$ relative to ensemble mean emissions (b).

data-constrained biomass burning inventories. In particular, we used a recently compiled monthly emission inventory at $1^{\circ} \times 1^{\circ}$ resolution from MOZART4 for the period 1996 to 2006. This inventory includes direct emissions from fossil-fuel/biofuel sources, based on Precursors of Ozone and their Effects in the Troposphere (POET) inventory (http://www.aero.jussieu.fr/projet/ACCENT/POET) and scaled to have regional magnitudes consistent with estimates of optimized emissions from inverse modeling using $\mathrm{MO}$ PITT for the year 2000 (Pétron et al., 2004). This inventory also includes biomass burning sources, based on GFEDv2 dataset (van der Werf et al., 2006) for 1996-2004. Emissions from biomass burning for 2005-2006 are taken from a climatological mean of GFEDv2 and scaled with year-specific MODIS Climate Modeling Grid 8-day fire product (Giglio et al., 2006). The compiled emission inventory, $\boldsymbol{\mu}_{\mathrm{emis}}$, is then perturbed assuming that the monthly emission $\boldsymbol{x}_{\mathrm{emis}}$ is $\log$-normally distributed with mean $\boldsymbol{\mu}_{\mathrm{emis}}$ and covariance $\Sigma_{\text {emis. }}$ The covariance $\Sigma_{\text {emis }}$ is the combination of sub-grid and inter-annual variability as well as estimates of regional magnitude uncertainties from inverse analyses (Arellano and Hess, 2006). Details on the construction of $\Sigma_{\text {emis }}$ are presented in Appendix A. In principle, we draw random samples of the distribution $p\left(\boldsymbol{x}_{\text {emis }}\right) \sim \ln \left(\boldsymbol{\mu}_{\mathrm{emis}}, \Sigma_{\mathrm{emis}}\right)$, and use these samples as members of the ensemble. These are then used as monthly emission input to CAM ensemble forecast cycle.

As an example, we show in Fig. 2 a spatial distribution of $\operatorname{diag}\left(\Sigma_{\text {emis }}\right)^{1 / 2}$ for April 2006. We note that in addition to the variability mainly coming from estimates in the inverse analyses, which is about $50 \%$ of the mean in most regions, there is also a large variability apparent in regions of frequent biomass burning consistent with our current understanding. We acknowledge however that this empiricallybased methodology is limited in various aspects especially as to its applicability to other emission and modeling studies. We view this approach simply as an interim solution to provide realistic estimates of direct emission ensembles for $\mathrm{CO}$ ensemble-based data assimilation.

For indirect emissions, which consist of $\mathrm{CO}$ sources from chemical oxidation of non-methane hydrocarbons and 
methane, we draw samples of the distribution $p\left(\boldsymbol{x}_{\text {chem }}\right)$ assuming a log-normal distribution with mean $\boldsymbol{\mu}_{\text {chem }}$ from MOZART4 full chemistry simulation and a covariance $\Sigma_{\text {chem }}$ whose square root of its diagonal elements is equal to $10 \%$ of $\mu_{\text {chem }}$. This is a simplification of the bulk uncertainty associated with this type of source, which certainly consists of various precursors that are non-linearly related and difficult to quantify.

\subsubsection{Ensemble of initial CO distribution}

The ensembles are generated using the ensembles of CAM initial conditions (Sect. 2.3.1) and emissions (Sect. 2.3.2). We start off by using a single CO initial condition from a previous MOZART4 simulation. We allow the $\mathrm{CO}$ in the model to be propagated forward in time, to gain sufficient variance, as each member of the ensemble of CAM initial conditions are integrated for two weeks. The integration includes a randomly assigned CAM3 emission from members of the emission ensembles. As such, the CO states after spinup exhibit an equilibrated variability due to coupled perturbations of the dynamical states and emissions. We used this ensemble of $\mathrm{CO}$ states as our ensemble of $\mathrm{CO}$ initial conditions. A sample of the mean and spread of the ensemble are shown in Fig. 3. As can be expected, the variability of $\mathrm{CO}$ is large in regions where there is a strong direct $\mathrm{CO}$ source (i.e. east Asia, northern Africa) and also in regions where transport can have significant impact (i.e. Pacific basin). We also find that the variability of $\mathrm{CO}$ has equilibrated across all regions after about 5 to 7 days.

\subsection{Observations}

The current DART/CAM global system has the ability to assimilate both meteorological and chemical observations. For the system's initial development and evaluation, we focus on assimilating a subset of available meteorological data currently used in NWP centers and satellite-derived CO retrievals from the MOPITT instrument. The following sections briefly describe these observations within the context of this assimilation system.

\subsubsection{Meteorological observations}

We use the meteorological observations processed at National Centers for Environmental Prediction (NCEP) (http:// dss.ucar.edu/datasets/ds351.0). These data are taken from radiosondes, pibals and aircraft reports collected by the Global Telecommunications System (GTS), and from satellite data processed at National Environmental Satellite, Data and Information Service (NESDIS). These are used as primary input to the NCEP Global Data Assimilation System (GDAS) for producing operational forecasts and final meteorological analyses. Here, we use a subset of these data including observations of temperature $(T)$ from radiosondes and observations of horizontal wind velocities $(U, V)$ from radiosondes
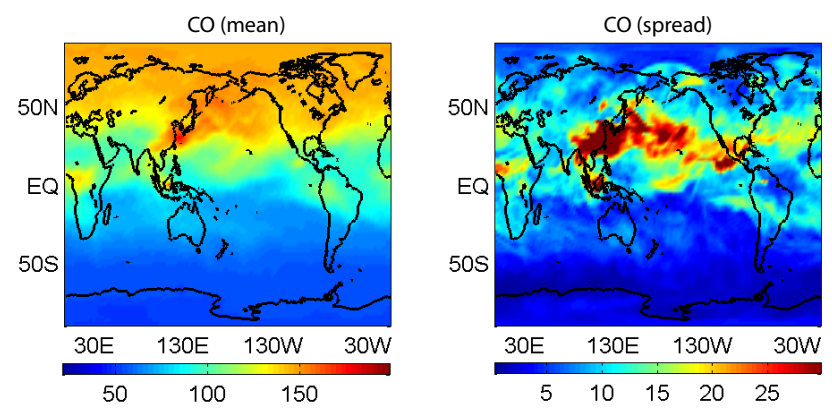

Fig. 3. Ensemble-mean (left panel) and ensemble-spread (right panel) of initial conditions of CAM3 $\mathrm{CO}$ in ppbv at $500 \mathrm{hPa}$ for 1 April 2006.

and cloud drift analysis (or satwind). We selected this small subset to simplify our evaluation of the system performance. Also, this particular setup for DART/CAM only assimilates observations of a subset of meteorological state variables (i.e. $T, U, V)$. However, it uses these observations to influence other model state variables such as surface pressure. Further details of the assimilation setup are discussed in Sect. 3.

We use a limited quality control on top of NCEP data protocol for these observations. In particular, we limit observations below $150 \mathrm{hPa}$ and observations with values within three standard deviations from the expected observations derived from the model. We also assign associated observation errors based on reported instrument uncertainties (i.e. on average, $\sim 3-4 \mathrm{~m} / \mathrm{s}$ for satwind, $\sim 1-2 \mathrm{~m} / \mathrm{s}$ for radiosonde wind and $\sim 0.8 \mathrm{~K}$ for radiosonde temperature).

\subsubsection{MOPITT CO retrievals}

We use the satellite-derived CO observations from MOPITT satellite instrument on board the NASA Terra satellite (http://mopitt.eos.ucar.edu/mopitt). It has a horizontal resolution (in nadir view) of about $22 \times 22 \mathrm{~km}^{2}$ and offers near-global coverage within 3-5 days. The MOPITT instrument provides $\mathrm{CO}$ retrieved profiles based on measured radiances in a $4.7 \mu \mathrm{m}$ thermal channel for cloud-free pixels and pixels covered by low clouds. The reported profiles nominally represent 7 vertical levels in the troposphere (surface, $850,700,500,350,250,150 \mathrm{hPa}$ ). However, these profiles are strongly correlated, exhibiting vertical sensitivities which are limited only within the free troposphere (Deeter et al., 2004). For our purposes, we use a subset of the $\mathrm{CO}$ observations by only using $\mathrm{CO}$ retrievals having high measurement sensitivity and physically realistic mixing ratios. In particular, we use MOPITT v3 Level $2700 \mathrm{hPa}$ retrievals having less than $50 \%$ retrieval a priori contribution and mixing ratios greater than $30 \mathrm{ppbv}$. Our quality control, which is mainly based on MOPITT data quality statement (http://mopitt.eos.ucar.edu/mopitt/data), ensures that we use $\mathrm{CO}$ observations that are reasonably representative of the true $\mathrm{CO}$ states. We use the retrieval associated averaging kernel, 

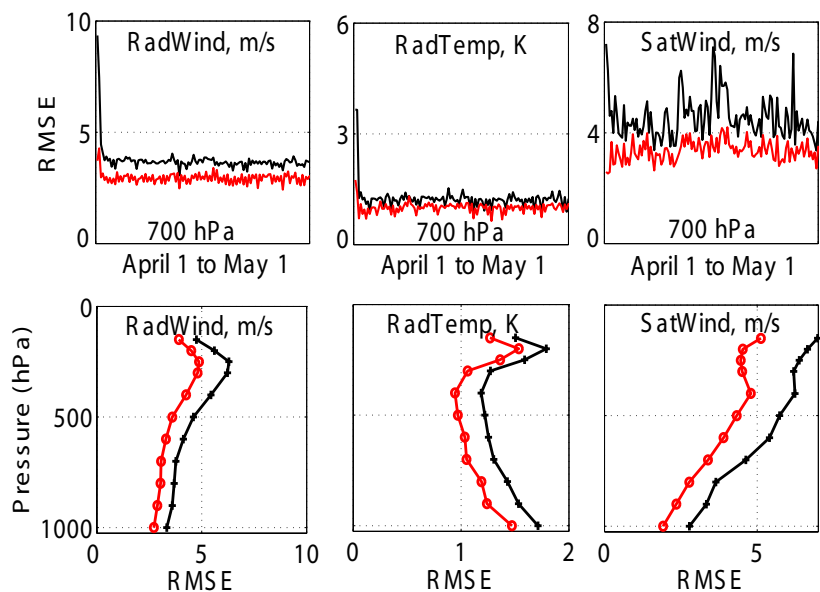

Fig. 4. Global root-mean-square error of prior (black) and posterior (red) ensemble-mean relative to observations of radiosonde horizontal wind velocity, radiosonde temperature and satwind horizontal wind velocity for the entire assimilation period (April 2006). Lower panels correspond to global RMSEs in the vertical using all observations over the same period.

which is a measure of the vertical sensitivity of the measurement, as an additional observation operator in the assimilation system. We note that the broad averaging kernel exhibited by MOPITT retrievals implies assimilating a partial $\mathrm{CO}$ column observation instead of a typical point observation (see also Sect. 4). Although we recognize that our selection criteria limit the full use of available information provided by MOPITT, again we use this subset to simplify our evaluation of the system. The selected CO retrievals are assumed in this work to be independent and unbiased with observation error of $10 \%$ of the CO retrieved mixing ratio (Emmons et al., 2004). The unbiased assumption is verified and discussed later in this paper (Sect. 4.2).

\section{Assimilation experiments}

Two sets of assimilation experiments are carried out to test and evaluate the performance of DART/CAM system. First, we conduct a reference $\mathrm{CO}$ simulation (REFSIM), consisting of a 20-member ensemble, which sequentially assimilates meteorological observations for the whole month of April 2006. This simulation is similar to a free-running offline GCTM simulation of CO, which may be driven by either assimilated meteorology (i.e. Global Modeling and Assimilation Office, GMAO) or reanalysis meteorology (i.e. NCEP or European Centre for Medium-Range Weather Forecast, ECMWF). The second experiment (COASSIM) involves a 20-member ensemble simulation of $\mathrm{CO}$ assimilating both meteorological observations and MOPITT CO retrievals over the same period. In combination, these two experiments pro- vide insights on how well tracer transport is represented in the model.

As mentioned in Sect. 2.1, the current system is configured so that the meteorological observations of temperature and wind velocities statistically influence the model state variables, namely, surface pressure, temperature, horizontal velocity, specific humidity, cloud ice and cloud water but not $\mathrm{CO}$. In contrast, the $\mathrm{CO}$ observations only statistically influence the $\mathrm{CO}$ state variable. In a statistical sense, it is possible that the $\mathrm{CO}$ observations can influence the other state variables and that the meteorological observations can impact the CO state. However, this EnKF feature is not applied in the present experiments.

In addition to localizing the impact of observations to a subset of state variables, a physically-based localization is also implemented for all types of observations. The observational impact is localized by multiplying a correlation function (from Gaspari and Cohn, 1999) to the flow-dependent covariances between the prior state variables and observation variables. We use a half-width of $\sim 1200 \mathrm{~km}$ in the horizontal component of the correlation function for all types of observations. In the vertical, we use $\sim 2 \mathrm{~km}$ for all types of observations except MOPITT CO. Assimilation of MOPITT $\mathrm{CO}$ presents a particular difficulty since the retrieved profiles exhibit longer vertical length scales $(2-3 \mathrm{~km})$ than typical vertical length scales of DART/CAM CO $(\sim 1 \mathrm{~km})$. And so, we adjust the calculated vertical correlation distance between the observed $\mathrm{CO}$ and the $\mathrm{CO}$ state variable such that the effective correlation function exhibits broader vertical length scales comparable to MOPITT. By effectively broadening the vertical localization, this adjustment only partially accounts for the scale mismatch between a partial column observation and the model. A more appropriate transformation should be used in future assimilation of this type of observation to fully account for the apparent scale mismatch. Details on the scale mismatch between satellite retrieved profiles and global chemical transport models will be discussed in a separate paper (Arellano, A. F. and Hess, P. G.: Ensemble-based estimates of CO sensitivity during INTEX-B field mission, manuscript in preparation).

\section{Results and discussions}

\subsection{Summary statistics of assimilation experiments}

Shown in Fig. 4 are global comparisons of the meteorological observations and the expected observations of model variables, represented as ensemble means of the forecast (prior) and analysis (posterior). Figure 5 corresponds to the ensemble spreads or standard deviations (both prior and posterior) of the model variables across the 20-member ensembles. These results correspond to both assimilation experiments (REFSIM and COASSIM) as the two are identical in their configuration for assimilating meteorological observa- 

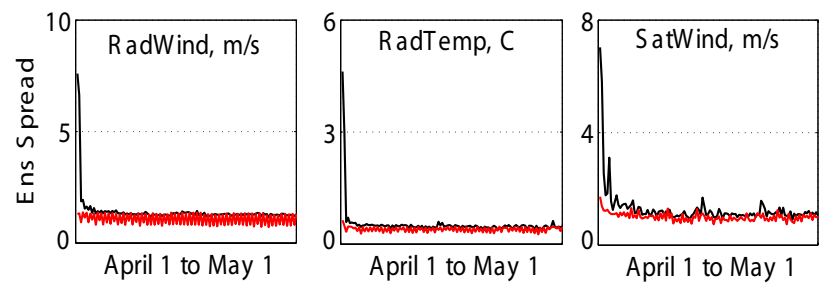

Fig. 5. Corresponding global prior (black) and posterior (red) ensemble-spread of expected observations for radiosonde horizontal wind velocity, radiosonde temperature and satwind horizontal wind velocity for the entire assimilation period (April 2006).

tions. The plots in Fig. 4 show that the predicted temperature and horizontal velocities are significantly improved in terms of root-mean-square errors (RMSEs) and bias relative to radiosonde and satwind observations used in the assimilation. In fact, the RMSEs for both model variables are reasonably close to the error range of radiosonde and satwind observations, pointing to low errors in the assimilation. This is also evident in the ensemble spread shown in Fig. 5, which also shows rapid reduction over the first few assimilation cycles. However, the error estimate, which is represented here as the ensemble spread, is less than the RMSE relative to observations. This appears to suggest an insufficient variance of the ensemble and an underestimation of the uncertainty of the modeled states. Even so, it is clear from these results that the mean of the system rapidly converges to observed temperature and wind velocities within 2-3 days of assimilation. Regional comparisons (not shown here) suggest a convergence rate in the data-dense Northern Hemisphere region of about 2 days and about 5 days in the Southern Hemisphere region.

Assimilating MOPITT CO retrievals in COASSIM experiment also show similar improvements in terms of RMSE and bias (Fig. 6, left panel). Globally, the posterior ensemble mean of expected $\mathrm{CO}$ observations has an RMSE of about 11 ppbv and bias of about 1-2 ppbv relative to MOPITT retrievals. The resulting ensemble spread for $\mathrm{CO}$ (Fig. 6, right panel) has also dropped significantly during the first few assimilation cycles indicating that information from the retrievals are being integrated effectively into the model space. The rate of model convergence to observed $\mathrm{CO}$ is longer than the convergence of meteorological variables to observed meteorology due to the larger variability of $\mathrm{CO}$ over its source regions and the longer period for the MOPITT instrument to achieve near-global coverage ( $\sim 3-5$ days). The nature of MOPITT retrievals, which exhibit broader vertical structures than typical point observations, potentially slows down the convergence as well.

\subsection{Verification with other datasets}

Results of the assimilation experiments are verified using two main datasets. First, the assimilated meteorological variables
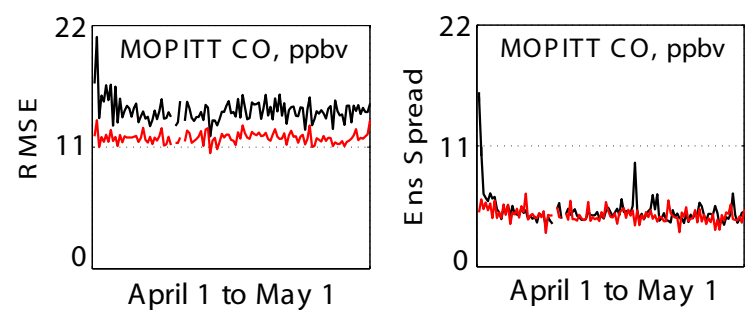

Fig. 6. Global RMSE of prior (black) and posterior (red) ensemblemean CO relative to MOPITT CO (left panel) and their corresponding ensemble-spread (right panel) for the entire assimilation period (April 2006). Global bias relative to MOPITT is $\sim 2.14 \mathrm{ppbv}$ for prior ensemble-mean and $\sim 1.55$ ppbv for posterior ensemble-mean.

are compared for the same time period with the analysis of the NCEP Global Forecast System (GFS) product. This dataset is currently used as input meteorology by several offline GCTMs (e.g. MOZART4). This comparison provides a means of assessing the ability of DART/CAM assimilation system to represent key components of tracer transport in a GCTM. It is recognized however that this dataset does not serve as an independent verification since the NCEP GFS uses similar observational dataset (e.g., but with additional data) in its assimilation system.

The modeled CO states are compared with an independent CO dataset from the second phase of the NASA INTEX-B field mission, which was conducted during Spring of 2006 (17 April-15 May). This intensive field campaign aimed at sampling chemical (pollution) outflow from Asia and at assessing its long-range transport across the Pacific and impact over North America. This is an especially good opportunity to evaluate the model performance of the DART/CAM system and its potential for chemical weather forecasting. Our verification focuses on the April campaign period for NCAR C-130 flights over the northeast Pacific basin and for NASA DC-8 flights out of Hawaii. Shown in Fig. 7 are the flight tracks for C-130 and DC-8 aircrafts for this period. Both aircrafts carried $\mathrm{CO}$ instrumentations, in particular an aerolaser fast-response carbon monoxide analyser on board C130 (by T. Campos) and a Differential Absorption CO Measurement (DACOM) spectrometer system on board DC-8 (by G. Sachse).

\subsubsection{Meteorological variables}

As shown in Fig. 8, the ensemble-mean analyses of horizontal wind velocities averaged over the month of April 2006 are remarkably similar to the NCEP GFS product. The plots show a high degree of similarity both in terms of magnitude and spatial structure demonstrating a decent performance of DART/CAM assimilation system relative to GFS, given also that only a subset of NCEP observations was used in DART/CAM assimilation. The similarity is particularly clear in the Northern Hemisphere where the data is dense. Differ- 

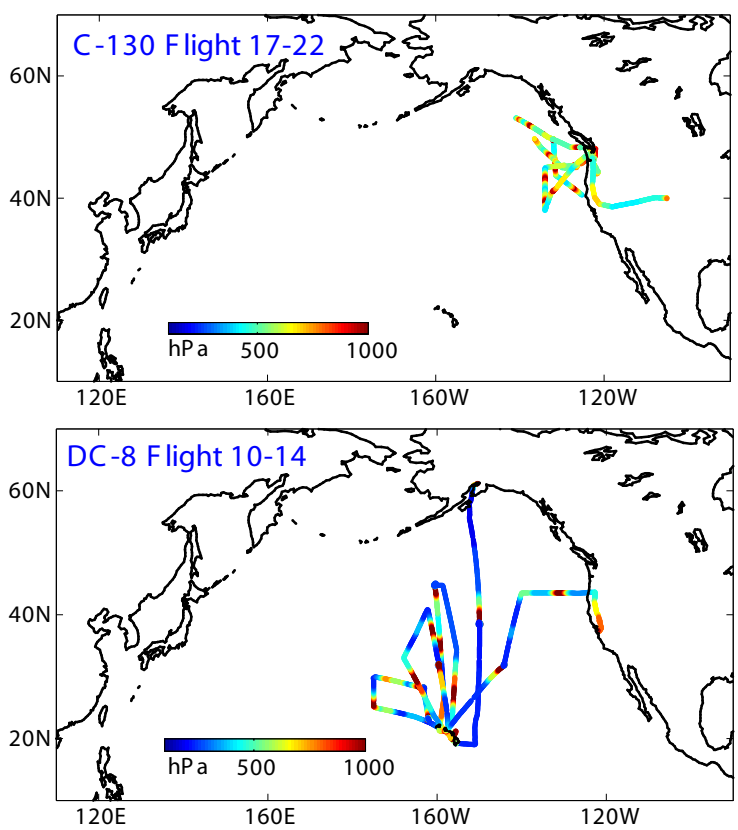

Fig. 7. INTEX-B flight tracks for NSF/NCAR C-130 and for NASA DC-8 during 17 April to 1 May 2006 campaign period. Colors represent the corresponding flight altitudes in $\mathrm{hPa}$.

ences can be seen mostly in the Southern Hemisphere, especially in the tropical Pacific, coastal regions in India, central Africa and in the polar region. The difference can be attributed to the difference in the model used for the assimilation system and the larger density of data (e.g. satellite) in the Southern Hemisphere used in GFS than in this work. Nonetheless, the comparison provides confidence in the fidelity of DART/CAM to represent realistic transport drivers in the global model.

\section{$4.2 .2 \mathrm{CO}$}

Our system verification for $\mathrm{CO}$ is summarized in Fig. 9a. These are Taylor diagrams showing the distance of modeled $\mathrm{CO}$ from observed $\mathrm{CO}$ defined in terms of correlation $(R)$, root-mean-square error (RMSE) and bias. Results are shown for both the experiment with MOPITT assimilation (COASSIM) and without MOPITT assimilation (REFSIM). Based on Taylor (2001), a typical RMSE metric $(E)$ can be decomposed into two orthogonal components, a bias term $(\bar{E})$ and a pattern RMS difference $\left(E^{\prime}\right)$. That is,

$E^{2}=\bar{E}^{2}+E^{\prime 2}$

where

$E^{\prime 2}=\sigma_{f}^{2}+\sigma_{r}^{2}-2 \sigma_{f} \sigma_{r} R$

such that $\sigma_{f}$ and $\sigma_{r}$ correspond to the standard deviation of the modeled $\mathrm{CO}$ concentration and the observed $\mathrm{CO}$ concentration, respectively; and $R$ corresponds to the correlation between the modeled and observed CO concentration. We can
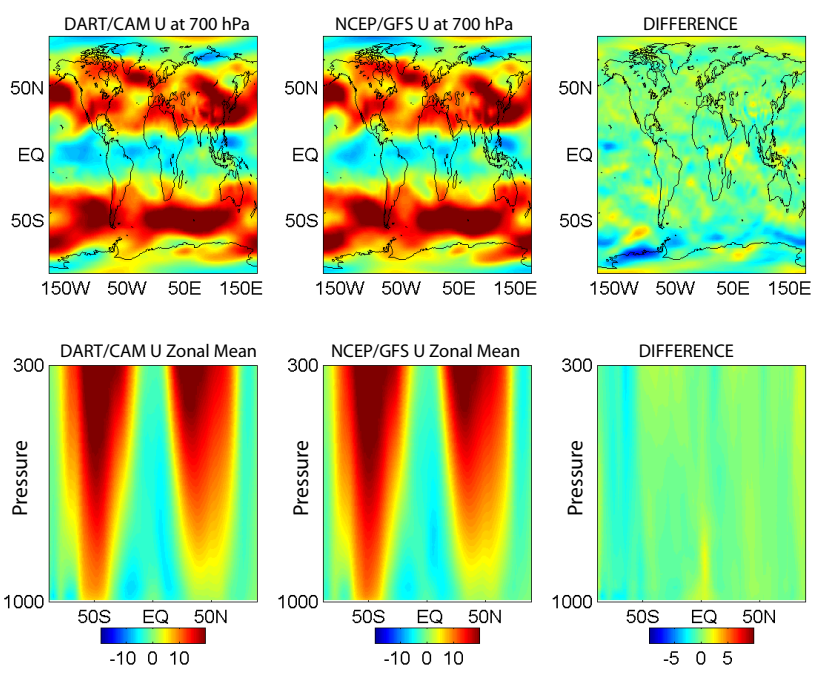

Fig. 8a. Global comparison of April 2006 mean horizontal wind component $(U)$ in $\mathrm{m} / \mathrm{s}$ from DART/CAM assimilation and NCEP/GFS forecast/analysis product (regridded to $2^{\circ} \times 2.5^{\circ}$ ). The upper panels correspond to $700 \mathrm{hPa}$ distribution while the lower panels correspond to zonal distribution (vertical axis in $\mathrm{hPa}$ ).
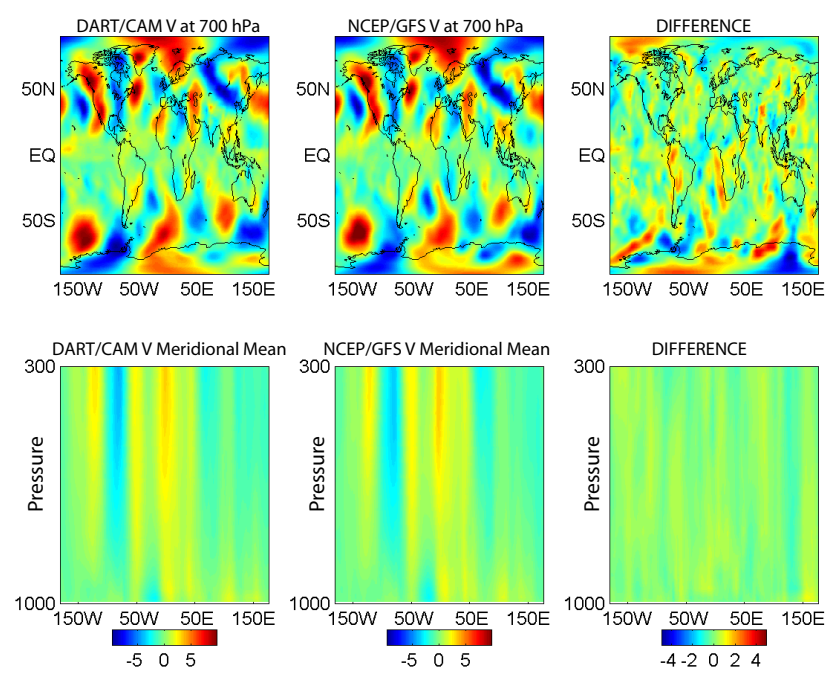

Fig. 8b. Global comparison of April 2006 mean horizontal wind component $(V)$ in $\mathrm{m} / \mathrm{s}$ from DART/CAM assimilation and NCEP/GFS forecast/analysis product (regridded to $2^{\circ} \times 2.5^{\circ}$ ). The upper panels correspond to $700 \mathrm{hPa}$ distribution while the lower panels correspond to meridional distribution (vertical axis in $\mathrm{hPa}$ ).

then construct a diagram which shows these relationships, by plotting $\sigma_{f}$ and $\sigma_{r}$ as distances from the origin in a polar graph (see Fig. 9b), with the angle represented as the arccosine of $R$. The shortest distance between the modeled and observed quantity represents the pattern RMS difference (or unbiased RMSE). We can also extend this to indicate overall means, by attaching to the plotted model quantity, a line segment that is perpendicular to the line defined by $E^{\prime}$ and 

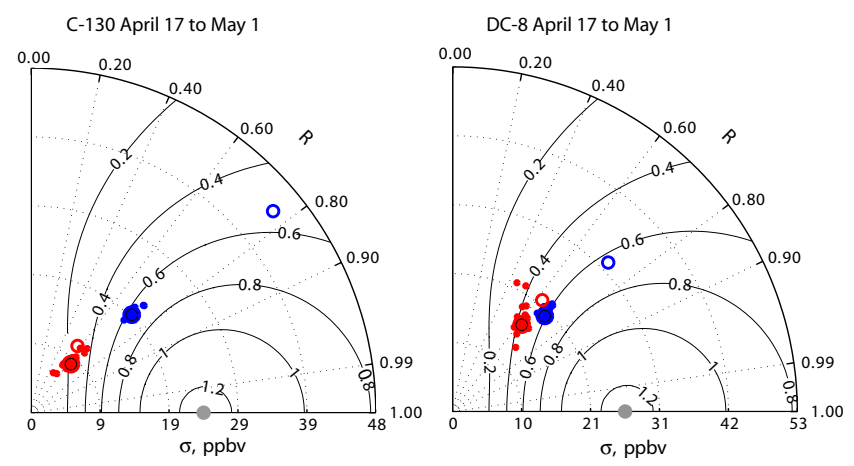

Fig. 9a. DART/CAM model skills relative to INTEX-B flight observations (gray). The blue dots represent the model skills for each ensemble member of DART/CAM with MOPITT assimilation (COASSIM) while red dots correspond to DART/CAM without MOPITT assimilation (REFSIM). Large filled circles correspond to ensemble-mean of analyses with the unfilled circles representing the total RMSE (see Fig. 9b).

whose distance is equal to $\bar{E}$. The distance from the obs quantity to the extended model quantity is then equal to $E$. A best fit to observations is typically interpreted to exhibit the smallest pattern difference. However, we can also define a skill score which summarizes the relationship between the modeled and observed CO concentrations. Here, we defined a skill $S$ as:

$S=\frac{4(1+R)^{4}}{\left(\hat{\sigma}_{f}+1 / \hat{\sigma}_{f}\right)^{2}\left(1+R_{0}\right)^{4}}$

where $\hat{\sigma}_{f}$ is the ratio of $\sigma_{f}$ and $\sigma_{r}$, and $R_{0}$ is the maximum potentially realizable correlation, assumed here to be 0.90 based on assimilated $\mathrm{CO}$ and MOPITT comparisons. This skill score, which is based on Eq. (5) of Taylor (2001), is superimposed as contours in Fig. 9a. Unlike typical skill scores, this skill score places more emphasis on modeled CO that is highly correlated with observations and that exhibits better simulation of the pattern difference. The skill approaches unity as $\sigma_{f}$ approaches to $\sigma_{r}$ and as $R$ approaches to $R_{0}$. It is also interpreted to decrease with increasing RMSE but with additional penalty for low correlation and low model variability. Note that the skill also depends on maximum realizable correlation $R_{0}$, which in this case, is assumed to be lower than a perfect correlation of 1 . This means that a perfect skill score (or most skillful model) will have a range from 1 to about 1.2 since it is relax towards achieving a correlation of $R_{0}$ as well.

It is clear from the diagrams in Fig. 9a that the assimilation of MOPITT retrievals improves the pattern statistics in modeled $\mathrm{CO}$ when compared to both $\mathrm{C}-130$ and $\mathrm{DC}-8$ flight observations. The ensemble mean of REFSIM CO has a correlation of 0.63 and 0.62 for C-130 and DC- 8 respectively, while the COASSIM CO shows an improved correlation of 0.72 (C-130) and 0.68 (DC-8). In terms of model

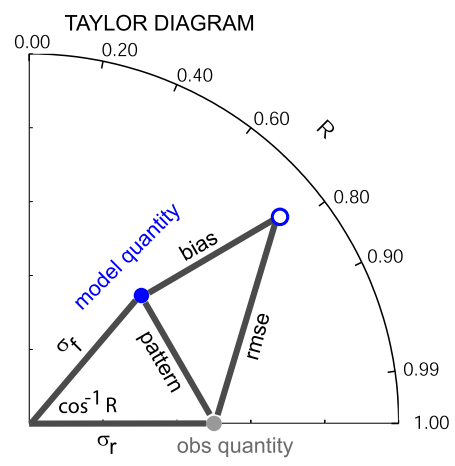

Fig. 9b. Taylor diagram representation of correlation $(R)$, RMSE and bias of modeled $\mathrm{CO}$ relative to observation (based from Taylor, 2001).

skill, COASSIM shows a skill of about 0.6 in contrast to REFSIM which has a skill of about 0.2 to 0.4 . This improvement is attributed to the increase in modeled $\mathrm{CO}$ variability and correlation, and is significant at $99 \%$ confidence given the spread of the model skill for all ensemble members.

Also apparent from the Taylor diagrams is the increase in bias on the COASSIM CO relative to REFSIM CO. As noted in Sect. 4.1, the assimilation of MOPITT retrievals in DART/CAM, which has a global bias of about 1-2 ppbv relative to MOPITT, implies that the assimilated $\mathrm{CO}$ is very close to MOPITT CO and exhibits low error associated with the assimilation. This suggests that the assimilated $\mathrm{CO}$ is a good surrogate for MOPITT. The bias observed relative to INTEX$\mathrm{B} \mathrm{CO}$ therefore is primarily due to the bias of MOPITT retrievals relative to INTEX-B. Such comparison with independent observations demonstrates the utility of an assimilation system in validating and comparing non-coincident datasets and measurements with complex observation operators. The positive bias observed in MOPITT is approximately 23-27 ppbv for C-130 CO and 11-14 ppbv for DC-8 $\mathrm{CO}$. Based on two $\mathrm{CO}$ data inter-comparisons conducted during the 2nd phase of INTEX-B, it is possible that differences in the bias between C-130 and DC- 8 observed by the assimilation can be mainly attributed to instrument discrepancies on board the two aircrafts. The DC-8 CO appears to be 5-10 ppbv higher than $\mathrm{C}-130 \mathrm{CO}$. That is, the ratio of DC- $8 \mathrm{CO}$ versus $\mathrm{C}-130 \mathrm{CO}$ is observed to be 1.08 from the two intercomparison analyses. The bias estimates are nonetheless in reasonable agreement with past and present MOPITT validations, which also report a positive bias in MOPITT retrievals of about $7-14 \%$ or $7-18$ ppbv at $700 \mathrm{hPa}$ (e.g. Emmons et al., 2004; Emmons et al., 2007). This apparent bias in the MOPITT retrievals with respect to this and other validation data is being investigated by the NCAR MOPITT team. It is expected that the next data reprocessing (version 4) which will include several retrieval enhancements will greatly reduce this discrepancy. Since the model verification is limited to the INTEX-B domain (Fig. 7), it is complicated to 
C-130 CO

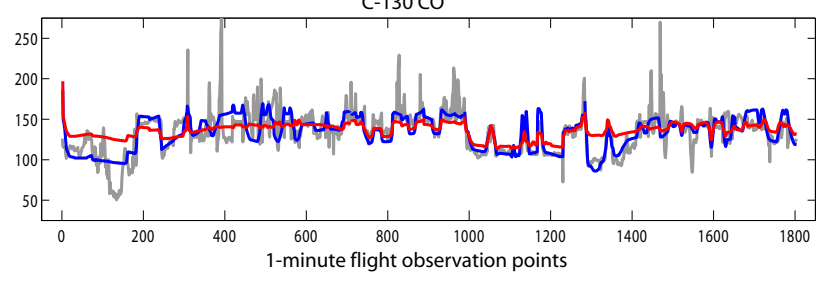

DC-8 CO

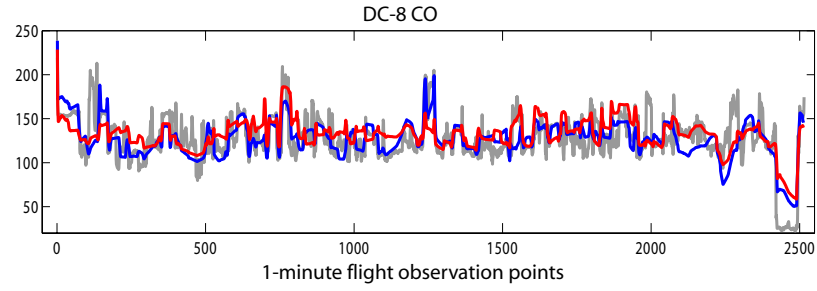

Fig. 10. COASSIM CO (ppbv) in blue and REFSIM CO in red relative to flight observations in gray during April field campaign. COASSIM CO is removed with observed bias (see Fig. 9a).

globally extrapolate the spatial variability of the bias (or the lack thereof) based only on the assimilated CO comparisons. More detailed investigations are necessary for proper global bias correction within the assimilation system (e.g. Lamarque et al., 2004; Dee, 2005).

Figures 10 and 11 are concatenations of 1-minute C-130 and DC-8 CO observation points for April campaign period, superimposed with the corresponding CO from REFSIM and COASSIM after removing the observed mean MOPITT bias (e.g. 25 ppbv for C-130, 13 ppbv for DC-8). The plots further show that MOPITT CO assimilation better captures the observed variability and improves the modeled vertical structure relative to INTEX-B observations, particularly for C$130 \mathrm{CO}$. We note however that the assimilation sometimes results in poor model prediction, for example, in DC-8 CO comparisons (Fig. 10) during a flight at the end of April (i.e. points from 1500 to 2100). Overall, while the model is able to capture the mean $\mathrm{CO}$ outflow from Asia and its transport to the NE Pacific, since it closely matched the magnitude of observed mean $\mathrm{CO}$ concentrations downwind of the source regions (Fig. 10), the simulation without MOPITT assimilation has difficulty simulating accurately the observed gradients and $\mathrm{CO}$ enhancements. This can also be seen in the averaged vertical structure (Fig. 11), expressed here as median vertical profile, where COASSIM CO is better correlated with the observed vertical structure than REFSIM CO. Given the difference in the shape of the observed and REFSIM vertical profiles, applying a simple bias correction for REFSIM would not significantly influence the improvement we find in COASSIM CO relative to observations. While our current system only assimilates $700 \mathrm{hPa}$ retrievals from MOPITT, there are indications that information at $700 \mathrm{hPa}$ is translated to nearby vertical levels through the ensemble covariances. The apparent improvement in model skill has
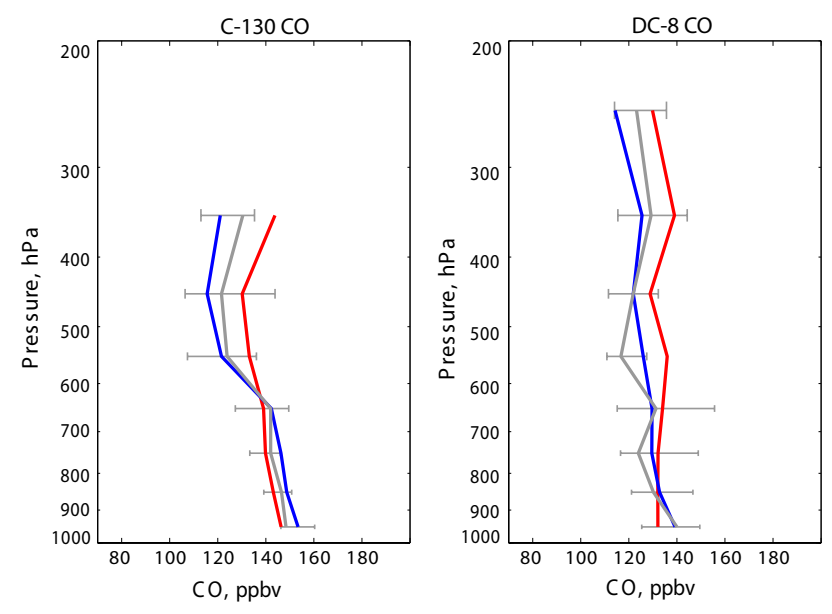

Fig. 11. Median vertical structure of COASSIM CO (ppbv) in blue and REFSIM CO in red relative to flight observations in gray. COASSIM CO is presubtracted with observed bias (see Fig. 9a). Observation error bars correspond to interquartile range calculated for each vertical bin.

important implications in particular to efforts in improving future chemical weather forecasts and GCTM predictability in general.

\subsection{CO distribution}

The CO distributions over the Pacific basin for REFSIM and COASSIM experiments are presented in Fig. 12. These are ensemble-mean $\mathrm{CO}$ at $700 \mathrm{hPa}$ averaged across the month of April. The COASSIM CO is uniformly reduced by $15 \%$ of its $\mathrm{CO}$ concentration to account for the apparent MOPITT bias over the region. This percentage is calculated such that the bias of COASSIM CO with INTEX-B CO is at its minimum, given the apparent $8 \%$ error between the two instruments. The COASSIM CO distribution shows a slightly different spatial structure than the REFSIM CO distribution. From a monthly-averaged perspective, the apparent $\mathrm{CO}$ enhancements at $700 \mathrm{hPa}$ over the northeastern Pacific in COASSIM $(\sim 150 \pm 3 \mathrm{ppbv})$ are not well represented in REFSIM ( $\sim 140 \pm 3$ ppbv). Over Asia, MOPITT assimilation sees more CO over eastern Siberia $(\sim 175 \pm 7$ vs. $\sim 165 \pm 5$ ppbv) and less over Shanghai, southern China and Burma ( $\sim 135 \pm 20$ vs. $165 \pm 20$ ppbv). There is some indication of a more dominant $\mathrm{CO}$ export pathway north of $40 \mathrm{~N}$ than an easterly boundary layer $\mathrm{CO}$ outflow from the source region in southern China. The import of Asian pollution to NE Pacific is slightly enhanced in COASSIM CO distribution. In contrast, there appears to be more CO in REFSIM over the tropical Pacific and extending to the west of California and Mexico, demonstring a more distinct hemispheric gradient in COASSIM. The differences in CO structure apparently suggest that some subtle features of $\mathrm{CO}$ sources, outflow and/or transport are not accurately represented in the 

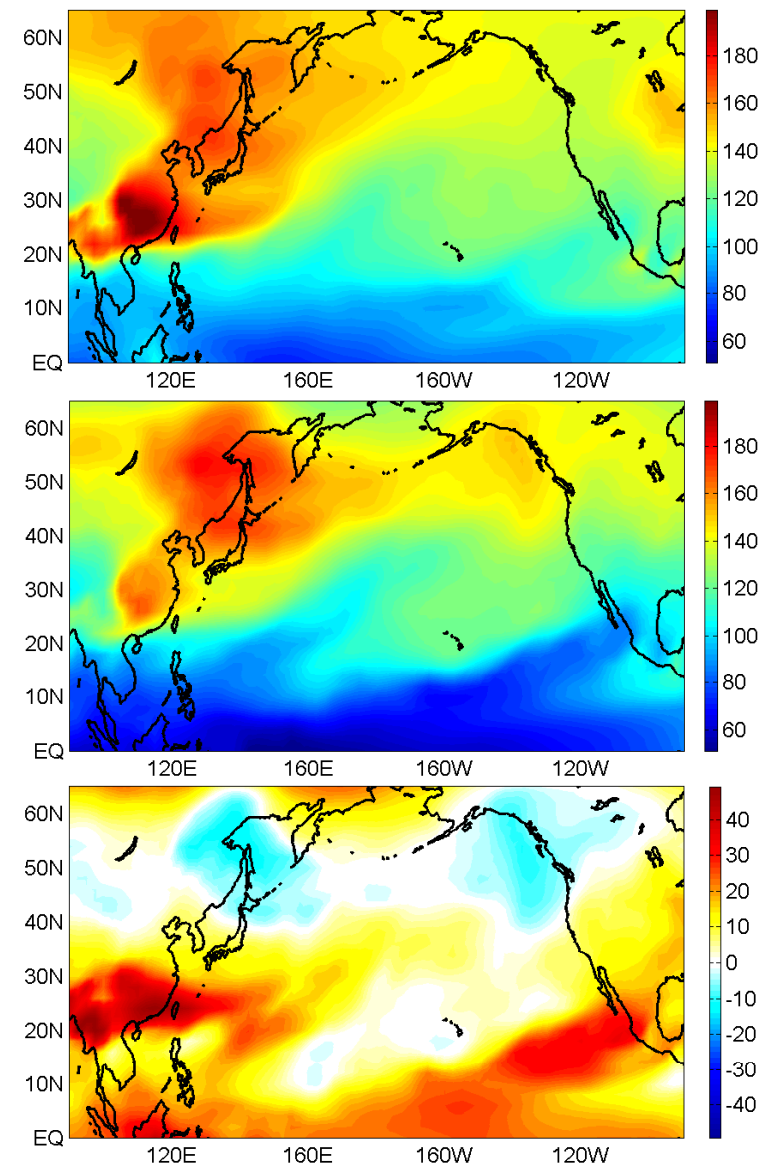

Fig. 12. Mean CO distribution (in ppbv) at $700 \mathrm{hPa}$ over the INTEX-B domain as depicted in DART/CAM analyses (top panel) REFSIM, (middle panel) COASSIM with observed MOPITT bias removed and (bottom panel) difference between REFSIM and COASSIM.

model. To some extent, this supports the previous results that while REFSIM reasonably simulates the large-scale features, it has difficulty capturing the $\mathrm{CO}$ variability and gradients observed in INTEX-B. In part, this can be attributed to the coarse resolution of the model where the observed variability may possibly be within the model sub-grid scales. The assimilation however is able to compensate for the lack of variability (and inherent model deficiencies) and hence provides a good source of model diagnosis.

\subsection{Illustration of $\mathrm{CO}$ forecast sensitivity}

Short-term regional forecasts require an even more accurate representation, particularly an initial condition that is close to observations. Representing the short-term variability on top of the mean flow patterns is critical in regional forecasts. This is true in forecasting pollution from Asia, which can be episodically transported to the NE Pacific within the time scales of 5 to 7 days depending on prevailing transport con-
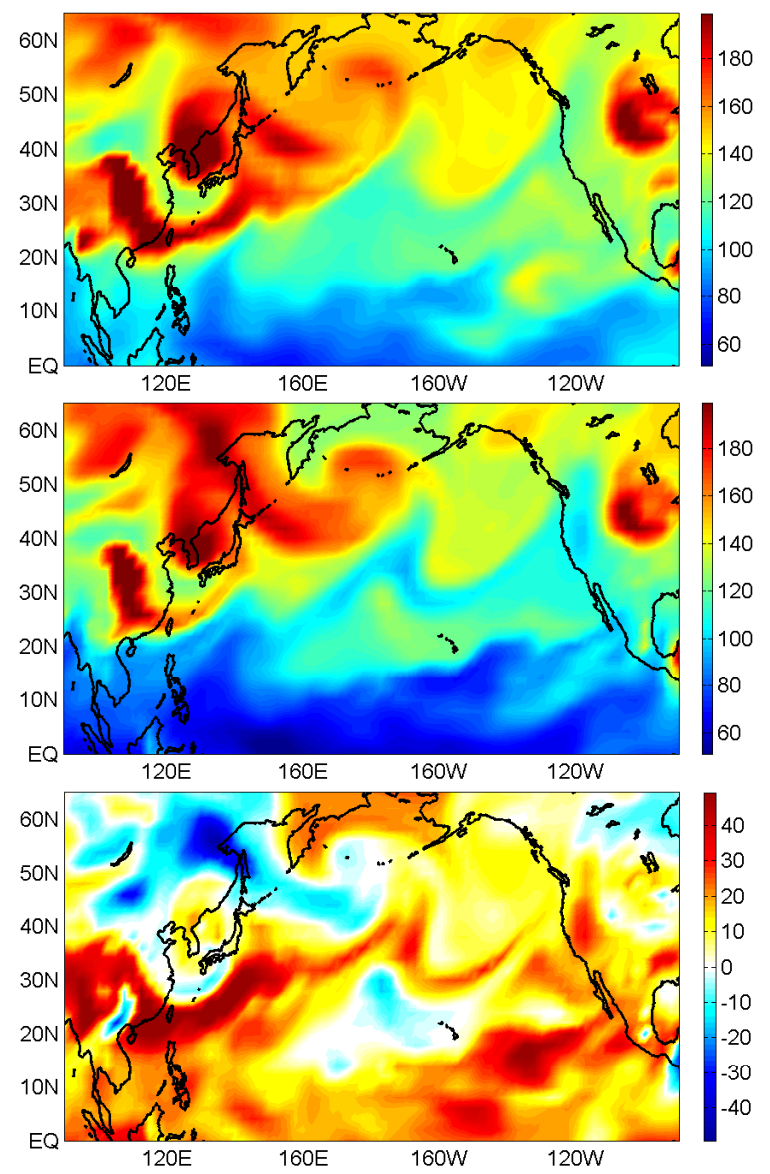

Fig. 13. Comparison of DART/CAM CO 3-day forecasts (top panel: forecast in ppbv at $700 \mathrm{hPa}$ valid for 20 April 2006 00:00 UTC from a free-running CO simulation (REFSIM), middle panel: forecast initialized with MOPITT-constrained CO at 17 April 2006 00:00 UTC, bottom panel: difference between the two forecasts).

ditions (Yienger, 2000; Jaffe et al., 1999). This highlights the role of initial condition in providing a fairly reliable forecast. In Fig. 13, we demonstrate the utility of the assimilation system to provide observationally-constrained $\mathrm{CO}$ initial conditions for $\mathrm{CO}$ forecasts. In addition to the two assimilation experiments, we conducted a 3-day forecast-mode experiment valid for 20 April 2006 00:00 UTC, which was initialized with bias-corrected COASSIM CO (see Sect. 4.3) at 17 April 2006 00:00 UTC. The difference shown in Fig. 13 is a comparison between the 3-day forecasts at $700 \mathrm{hPa}$ from REFSIM and the 3-day forecast at the same level using COASSIM initial condition. Differences of about $20-40 \mathrm{ppbv}$ are evident in regions of Asian outflow and along the frontal systems across the Pacific. The spatial patterns depicted in the figure illustrate the key role of observationally-constrained initial condition in producing accurate forecasts. This may have an effect on efforts like mission flight planning where the goal is to correctly track enhanced plumes of pollution. 

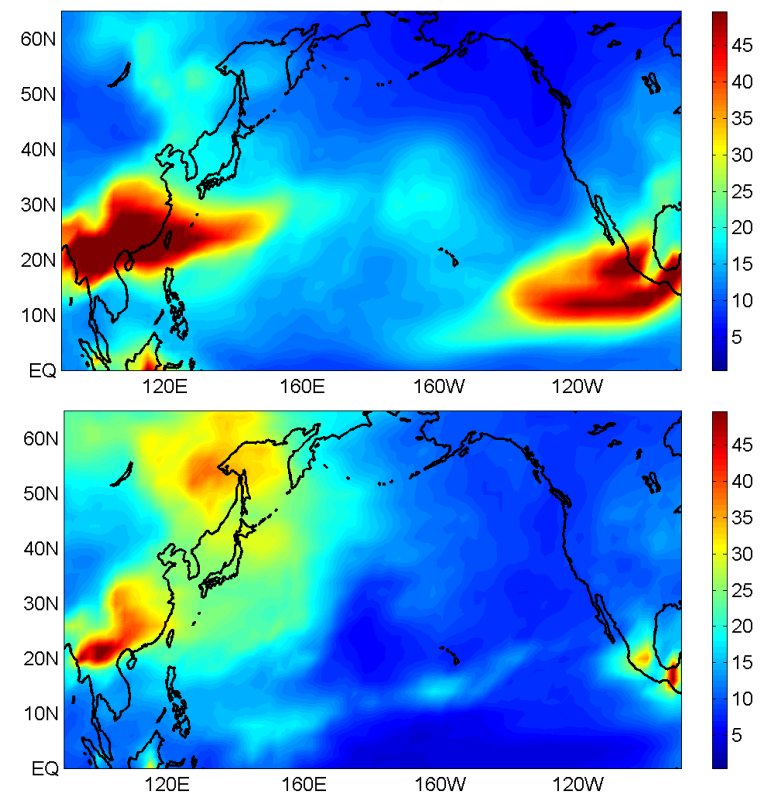

Fig. 14. Ensemble-spread (in ppbv) of DART/CAM CO at $700 \mathrm{hPa}$ within the INTEX-B domain averaged between 6 April to 1 May 2006. The upper and lower panels correspond respectively to ensemble spread from REFSIM (top panel) and COASSIM analyses (bottom panel).

\subsection{Estimates of model uncertainties}

\subsubsection{Ensemble spread}

The ensemble-based data assimilation system provides a probabilistic characterization of the $\mathrm{CO}$ state estimates. Here, we show the ensemble spread of modeled CO for REFSIM and COASSIM. Taken as the standard deviation of the predicted $\mathrm{CO}$ concentrations across the 20 ensemble members, the ensemble spread can be considered as a measure of uncertainty on the estimate of the CO states (or on how well the ensemble members agree on the $\mathrm{CO}$ forecast). As presented in Fig. 14, the ensemble spread of REFSIM CO is mainly characterized by a large spread in two source regions. This is most likely influenced by our large error estimates $(>50 \%)$ of biomass burning emissions in Southeast Asia and Central America (see Fig. 2) rather than the spread due to perturbations in meteorology. We expect this since the spread in meteorology is significantly reduced in the meteorological assimilation component of CDAS while the spread in emissions is fixed during the assimilation cycles and is not presently constrained. We see changes in the structure on the ensemble spread of COASSIM, with clear indications of transport-related uncertainties, such as an outflow east of China and Japan and a regional circulation over southeastern Siberia. Although not shown here, the flow-dependent patterns of variability as estimated from the mean ensem-

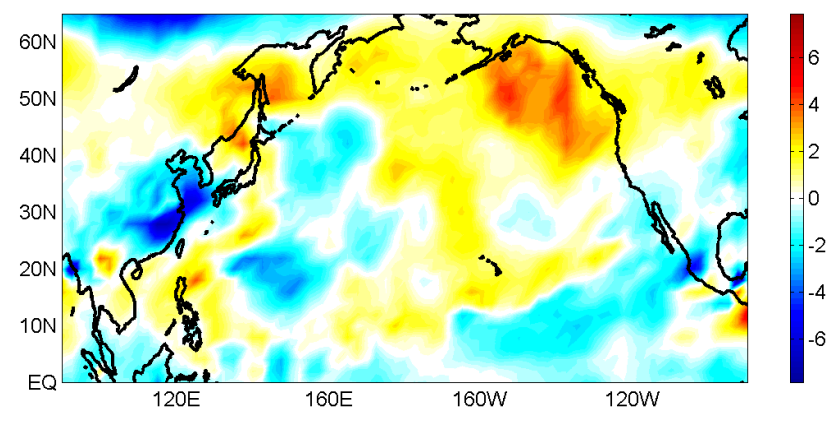

Fig. 15. Mean spatial distribution of analysis increments (Posterior $\mathrm{CO}$ - Prior CO, in ppbv) at $700 \mathrm{hPa}$ averaged between 6 April to 1 May 2006.

ble spread are consistent with the variability of the assimilated $\mathrm{CO}$ in the region as estimated from the standard deviation of ensemble-mean $\mathrm{CO}$ across the time period. To an extent, the COASSIM ensemble spread is an improvement in representing the structure of the uncertainties in the $\mathrm{CO}$ distribution since it appears to represent additional features other than emission uncertainties. However, when compared to the model RMSE relative to MOPITT (Fig. 6), the posterior ensemble spread still appears to be under-estimated especially in the downwind region, where the variability is mostly transport-induced. Such differences in the structure of the ensemble spread between COASSIM and REFSIM demonstrate the spatial variability of the error estimates and point to locations were the errors are apparently too small. For this reason, a more appropriate characterization of the uncertainties as estimated from the ensemble approach is to take advantage of the structure by conducting an analysis of the correlation in conjunction with an analysis of the variance.

\subsubsection{Mean analysis increments}

The assimilation system can also be used to diagnose model and/or observation errors. Following Dee (2005), we use the difference of $\mathrm{CO}$ analysis and forecast (or increments) to represent short-term systematic errors in the model. The adjustments in the $\mathrm{CO}$ forecast for each 6-hour assimilation cycle can be assumed to be mostly attributed to errors in the model. As previously discussed in Sect. 4.1, the errors from the assimilation methodology are relatively small. If it can be assumed that the assimilated $\mathrm{CO}$ has already converged to MOPITT CO after several assimilation cycles, then, the manner in which the systematic $\mathrm{CO}$ short-term forecast diverges from MOPITT CO largely relates to errors in the model. To illustrate, we took the 6-hourly ensemble-mean forecast $\mathrm{CO}$ and the analysis $\mathrm{CO}$ in the observation space and averaged over the INTEX-B domain (from equator to $65 \mathrm{~N}$ latitude, $90 \mathrm{E}$ to $90 \mathrm{~W}$ longitude). The resulting time series of the spatiallyaveraged observation increment describes the evolution of the forecast and analysis errors relative to assimilated MO- 
PITT retrievals. Similar to the global time series shown on the left panel of Fig. 6, the mean forecast RMSEs are systematically larger than the analysis errors. This difference represents the adjustment made in the analysis step to bring the modeled CO closer to observations. We can also take the temporal mean of these increments and look at its spatial distribution to explore characteristic regions where the modeled $\mathrm{CO}$ is frequently adjusted. Figure 15 shows the spatial distribution of the mean adjustments about the 6 April-1 May 2006 period. We specifically remove the first 5 days of assimilation to allow for spin-up in the assimilation. As shown, the model appears to overpredict in source regions (i.e. China and east of Asia) and underpredict in downwind regions (i.e. northeastern Pacific across the C-130 and DC-8 flight coverage). The mean adjustments are consistent with results discussed in the previous sections (e.g. Fig. 12). Additionally, this model error characteristic has been reported in other GCTM simulations. In particular, some offline GCTM results consistently report a negative bias in $\mathrm{CO}$ concentrations during Spring over Hawaii and Midway (e.g. Bey et al., 2001; Liang et al., 2004; Arellano et al., 2004). However, increasing Asian emissions to account for this bias degrades the model further over Asia. We note in particular that the ensemble-mean emissions of Asian CO (and other regions like Europe) used in DART/CAM have already been optimized following Pétron et al. (2004). The spatial structure provides further evidence of a GCTM related error, which can not be readily explained by emissions alone. It is a bulk error that appears to be a combination of errors due to transport, emissions and/or chemistry. It is possible that the modeled $\mathrm{CO}$ is transported slightly differently from what is observed by MOPITT and/or the modeled chemical production of $\mathrm{CO}$ from hydrocarbon oxidation during transport is underestimated. While further analysis is necessary to identify the sources of this error, knowledge of model error is useful in providing a consistent inverse analysis. Without a reasonable model error estimate, results of inverse analyses will be largely sensitive to the choice of the observation domain and the proximity of the observations to the source location of interest.

\section{Conclusions}

We have introduced a new global chemical data assimilation system based on an ensemble Kalman filter approach. The system interfaces CAM3 global atmosphere model with simplified chemistry into the DART ensemble framework. Such an ensemble-based data assimilation system is appealing for studies in global chemical transport as it offers the flexibility and efficiency to assimilate measurements with various scales and of various chemical species. This is especially true, at present, in light of the availability of near-global and long-term chemical observations.
One of the goals of this work is to demonstrate the utility of the system to studies related to chemical weather forecasts, focusing initially on assessing its model performance on Asian CO outflow and its episodic transport to North America during the INTEX-B field mission in April 2006. We apply the assimilation system in constraining the global tropospheric $\mathrm{CO}$ distribution within CAM3, by jointly assimilating observations of temperature and horizontal wind velocity as well as satellite CO retrievals from the MOPITT satellite instrument. Since the variability of $\mathrm{CO}$ is mainly induced by transport and emissions, a reasonable ensemble representation of $\mathrm{CO}$ is generated first. This includes representing an ensemble of initial meteorological conditions in CAM3, based on long-term climatological CAM3 simulations, together with an ensemble of total CO emissions, mainly based on our current estimates of emission uncertainties. The DART/CAM assimilation performance is verified using independent $\mathrm{CO}$ observations from $\mathrm{C}-130$ and $\mathrm{DC}-8$ flights during the field campaign. Assimilation results show that the current system converges to the observed MOPITT $\mathrm{CO}$ distribution within the first 5 days of assimilation, consistent with the duration of MOPITT obtaining near-global coverage. The DART/CAM analyzed meteorology also appears to be very similar in magnitude and structure to operational NCEP GFS analyses. Significant improvements in the model skill are evident with MOPITT assimilation (COASSIM), notably capturing the observed $\mathrm{CO}$ variability and improving the correlation between modeled CO and INTEX-B flight observations. We note however that the present model representation of CO with no MOPITT assimilation (REFSIM) generally captures the large-scale $\mathrm{CO}$ outflow. This can be mostly attributed to optimized estimates of Asian anthropogenic emissions. Also, the activity of biomass burning in the region, which largely accounts for uncertainty in modeling CO emissions, is observed to be relatively low over NE Pacific during the campaign period.

Constraining $\mathrm{CO}$ using the assimilation system, and evaluating against independent set of measurements, provides important information on the MOPITT retrievals as well as on the fidelity of the model to represent $\mathrm{CO}$ transport over the Pacific. The assimilation reveals a slight positive bias in MOPITT CO, of about 10-18\% compared to INTEX-B mean $\mathrm{CO}$ concentration. The results demonstrates an important utility of the assimilation system in validating and comparing non-coincident datasets and measurements (like MOPITT) having complex observation operators. With removal of the observed bias in COASSIM CO, the assimilation results show evidence of monthly-mean $\mathrm{CO}$ loadings of about 150 ppbv over the NE Pacific, which is slightly higher than REFSIM CO $(\sim 140 \mathrm{ppbv})$. Furthermore, analysis of mean assimilation increments reveals a model error structure showing model overprediction of $\mathrm{CO}$ in the source regions of Asia and underprediction in downwind regions consistent with several offline GCTM simulations. Yet, it appears that the model error, depicted in this work as mean adjustments, 
cannot be solely explained, to the first order, as an underprediction in Asian emissions. Albeit limited in scope, these results have important implications in efforts to improve future regional $\mathrm{CO}$ forecasts and to inverse modeling of $\mathrm{CO}$.

\section{Appendix A}

\section{Construction of $\mathrm{CO}$ emission covariance}

The climatological monthly emission covariance, $\Sigma_{\text {emis }}$ is expressed as a combination of sub-grid variability $\Sigma_{G}$, interannual variability $\Sigma_{A}$ and uncertainty estimates on regional monthly totals of $\mathrm{CO}$ emissions from inverse analyses, $\Sigma_{I}$. That is,

$\sum_{\mathrm{emis}}^{m}=\sum_{G}^{m}+\sum_{A}^{m}+\sum_{I}^{m}$

where $m$ is the month index from 1 to 12 (i.e. January to December). $\Sigma_{\text {emis }}, \Sigma_{G}, \Sigma_{A}$ and $\Sigma_{I}$ are monthly covariance matrices whose dimensions are $n_{\text {grid }} \times n_{\text {grid }}$, where $n_{\text {grid }}=144 \times 91$ at $2^{\circ} \times 2.5^{\circ} \mathrm{CAM}$ horizontal resolution.

First, we divide the globe into 13 broad regions based on Arellano and Hess (2006). The covariance $\Sigma_{G}$ is constructed as a block diagonal matrix with block matrix elements $\mathbf{B}_{r, m}$, where $r$ is the region index from 1 to 13 . This matrix is defined as,

$\mathbf{B}_{r, m}=\operatorname{diag}\left(\boldsymbol{\sigma}_{\text {grid }, r}\right)^{2}$,

where $\sigma_{\text {grid, } r}$ is the standard deviation of $1^{\circ} \times 1^{\circ}$ grid emissions within each $2^{\circ} \times 2.5^{\circ} \mathrm{CAM}$ grid for a particular month, $m$ and region, $r$. In this work, this corresponds to the sub-grid variability specific for April 2006 emissions. That is,

$\sum_{G}^{4}=\left[\begin{array}{llll}\mathbf{B}_{1,4} & & & \\ & \ddots & & \\ & & \ddots & \\ & & \mathbf{B}_{13,4}\end{array}\right]$

The second covariance term, $\Sigma_{A}$, is associated with the spatial covariance of each emission grid point with its neighboring grids for a particular climatological month. However, the covariance is localized within a certain region. It is assumed that uncertainties across regions are independent. As such, $\Sigma_{A}$ is constructed as block diagonal matrix with each block corresponding to a particular region. We form a data matrix, $\mathbf{X}_{r, m}$ for each of the region and for each climatological month. Each matrix forms a dimension of $n_{\text {grid_region }} \times n_{\text {month }}$, where $n_{\text {grid_region }}$ is the number of model $2^{\circ} \times 2.5^{\circ}$ grids in a particular region and $n_{\text {month }}=10$ (e.g. compilation of each April from 1996 to 2006). We calculate empirically for each data matrix $\mathbf{X}_{r, m}$, a sample spatial covariance $\mathbf{C}_{r, m}$,

$\mathbf{C}_{r, m}=<\mathbf{X}_{r, m} \mathbf{X}_{r, m}^{T}>$.
We then smooth the sample covariance by doing an eigenvalue decomposition of $\mathbf{C}_{r, m}$ and retaining only its 3 leading eigenvectors. $\Sigma_{A}$ is constructed as a compilation of resulting smoothed covariances for all 13 regions. For example,

$$
\sum_{A}^{4}=\left[\begin{array}{cccc}
\mathbf{C}_{1,4} & & & \\
& \ddots & & \\
& & \ddots & \\
& & & \mathbf{C}_{13,4}
\end{array}\right]
$$

In this manner, we account for the spatial variability on a regional basis by assuming that the variability within each region is stationary in time across the period spanned by the inventory (i.e. 10 years).

The third covariance term, $\Sigma_{I}$, is also constructed as block diagonal matrix, where each block corresponds to an uncertainty estimate of total sum of emissions for each region. The estimates are taken from Arellano and Hess (2006) sensitivity analyses, where they reported a larger uncertainty in MOPITT CO inverse estimates for the year 2000 when a different treatment of tracer transport is used in the inverse model. We construct a diagonal covariance matrix $\mathbf{D}_{r, m}$ for each region and climatological month. This is calculated as:

$\mathbf{D}_{r, m}=\operatorname{diag}\left(\frac{\sigma_{r}}{100} \boldsymbol{\mu}_{\text {grid }, r}\right)^{2}$.

where $\sigma_{r}$ is the relative spread (in \%) of the total sum of annual emission for each region and $\boldsymbol{\mu}_{\mathrm{grid}, r}$ is the emission associated for each grid within the region. As such, for $m=4$,

$\sum_{I}^{4}=\left[\begin{array}{cccc}\mathbf{D}_{1,4} & & & \\ & \ddots & & \\ & & \ddots & \\ & & \mathbf{D}_{13,4}\end{array}\right]$

Acknowledgements. We thank the NCAR/MOPITT team for CO observations and the INTEX-B team for access to other field observations. We also acknowledge J.-F. Lamarque (NCAR/ACD) and J. Hacker (NCAR/MMM) for reviewing the initial manuscript and V. Yudin (NCAR/ACD) for helpful discussions. We thank T. Hoar (NCAR/IMAGe) for assistance with DART and F. Vitt (NCAR/ACD) for his help with CAM installation. This work is supported by NSF ITR Grant 115912 and by NASA Grant NN9069B279. The National Center for Atmospheric Research is operated by the University Corporation for Atmospheric Research under the sponsorship of the National Science Foundation.

Edited by: H. Singh

\section{References}

Allen, D. J., Kasibhatla, P. S., Thompson, A. M., et al..: Transportinduced interannual variability of carbon monoxide determined using a chemistry and transport model, J. Geophys. Res., 101, 28 655-28 670, doi:10.1029/96JD02984, 1996. 
Anderson, J. L. and Anderson, S. L.: A Monte Carlo implementation of the nonlinear filtering problem to produce ensemble assimilations and forecasts, Mon. Weather Rev., 127, 2741-2758, 1999.

Anderson, J. L.: An ensemble adjustment Kalman Filter for data assimilation, Mon. Weather Rev., 129, 2884-2903, 2001.

Anderson, J. L.: Exploring the need for localization in ensemble data assimilation using an hierarchical ensemble filter, Physica D, 230, 99-11, doi:10.1016/j.physd.2006.02.011, 2007a.

Anderson, J. L.: An adaptive covariance inflation error correction algorithm for ensemble filters, Tellus A, 59, 210-224, $2007 \mathrm{~b}$.

Arellano Jr., A. F., Kasibhatla, P. S, Giglio, L., et al.: Top-down estimates of global CO sources using MOPITT measurements, Geophys. Res. Lett., 31, L01104, doi:10.1029/2003GL018609, 2004.

Arellano, A. F. and Hess, P. G.: Sensitivity of top-down estimates of CO sources to GCTM transport, Geophys. Res. Lett., 33, L21807, doi:10.1029/2006GL027371, 2006.

Auger, L. and Tangborn, A. V.: A Wavelet-Based Reduced Rank Kalman Filter for Assimilation of Stratospheric Chemical Tracer Observations, Mon. Weather Rev., 132, 1220-1237, 2004.

Bey, I., Jacob, D. J., Logan, J. A., and Yantosca, R. M.: Asian chemical outflow to the Pacific in spring: Origins, pathways, and budgets, J. Geophys. Res., 106, 23 097-23114, doi:10.1029/2001JD000806, 2001.

Chai T., Carmichael, G. R., Sandu, A., et al.: Chemical data assimilation of Transport and Chemical Evolution over the Pacific (TRACE-P) aircraft measurements, J. Geophys. Res., 111, D02301, doi:10.1029/2005JD005883, 2006.

Clerbaux, C., Hadji-Lazaro, J., Hauglustaine, D., et al.: Assimilation of carbon monoxide measured from satellite in a threedimensional chemistry-transport model, J. Geophys. Res., 106, 15 385-15 394, doi:10.1029/2000JD900682, 2001.

Collins, W. D., Rasch, P. J., Eaton, B. E., et al.: Simulating aerosols using a chemical transport model with assimilation of satellite aerosol retrievals: Methodology for INDOEX, J. Geophys. Res., 106, 7313-7336, doi:10.1029/2000JD900507, 2001.

Collins, W. D., Bitz, C. M., Blackmon, M. L., et al.: The Formulation and atmospheric simulation of the Community Atmosphere Model Version 3 (CAM3), J. Climate, 19(11), 2144-2161, 2006.

Dee, D. P.: Bias and data assimilation, Q. J. Roy. Meteor. Soc., 131(613), 3323-3343, 2005.

Deeter, M. N., Emmons, L. K., Edwards, D. P., et al.: Vertical resolution and information content of $\mathrm{CO}$ profiles retrieved by MOPITT, Geophys. Res. Lett., 31, L15112, doi:10.1029/2004GL020235, 2004.

Dethof, A. and Hólm, E.: Ozone assimilation in the ERA-40 reanalysis project, Q. J. R. Meteor. Soc., 130, 2851-2872, 2004.

Eben, K., Juru, P., Resler, J., et al.: An ensemble Kalman filter for short-term forecasting of tropospheric ozone concentrations, Q. J. Roy. Meteor. Soc., 131, 3313-3322, 2005.

Elbern, H., Strunk, A., Schmidt, H., and Talagrand, O.: Emission rate and chemical state estimation by 4-dimensional variational inversion, Atmos. Chem. Phys., 7, 1-59, 2007, http://www.atmos-chem-phys.net/7/1/2007/.

Elbern, H. and Schmidt, H.: A four-dimensional variational chemistry data assimilation scheme for Eulerian chemistry transport modeling, J. Geophys. Res., 104, 18 583-18 598, 1999.

Elbern, H., Schmidt, H., Talagrand, O., and Ebel, A.: 4D-variational data assimilation with an adjoint air quality model for emission analysis, Environ. Modell. Software, 15, 539-548, 2000.

Emmons, L. K., Deeter, M. N., Gille, J. C., et al.: Validation of Measurements of Pollution in the Troposphere (MOPITT) CO retrievals with aircraft in situ profiles, J. Geophys. Res., 109, D03309, doi:10.1029/2003JD004101, 2004.

Emmons, L. K., Pfister, G. G., Edwards, D. P., et al.: Measurements of Pollution in the Troposphere (MOPITT) validation exercises during summer 2004 field campaigns over North America, J. Geophys. Res., 112, D12S02, doi:10.1029/2006JD007833, 2007.

Engelen, R. J. and McNally, A. P.: Estimating atmospheric CO2 from advanced infrared satellite radiances within an operational four-dimensional variational (4D-Var) data assimilation system: Results and validation, J. Geophys. Res., 110, D18305, doi:10.1029/2005JD005982, 2005.

Eskes, H. J., Van Velthoven, P. F. J., Valks, P. J. M., et al.: Assimilation of GOME total ozone satellite observations in a threedimensional tracer transport model, Q. J. Roy. Meteor. Soc., 129, 1663-1681, 2003.

Evensen, G.: Sequential data assimilation with a nonlinear quasigeostrophic model using Monte-Carlo methods to forecast error statistics, J. Geophys., Res., 99, 10 143-10 162, 1994.

Fisher, M. and Lary, D. J.: Lagrangian four-dimensional variational data assimilation of chemical species, Q. J. Roy. Meteor. Soc., 121, 1681-1704, 1995.

Frankenberg, C., Meirink, J. F., Bergamaschi, P., et al.: Satellite chartography of atmospheric methane from SCIAMACHY on board ENVISAT: Analysis of the years 2003 and 2004, J. Geophys. Res., 111, D07303, doi:10.1029/2005JD006235, 2006.

Gaspari, G. and Cohn, S. E.: Construction of correlation functions in two and three dimensions, Q. J. Roy. Meteor. Soc., 125, 723758, 1999.

Giglio, L., Csiszar, I., and Justice, C. O.: Global distribution and seasonality of active fires as observed with the Terra and Aqua Moderate Resolution Imaging Spectroradiometer (MODIS) sensors, J. Geophys. Res., 111, G02016, doi:10.1029/2005JG000142, 2006.

Granier, C., Müller, J.-F. , Pétron, G., et al.: A three-dimensional study of the global CO budget, Chemosphere, Global. Change Sci., 1, 255-261, 1999.

Hamill, T. M., Whitaker, J., and Snyder, C.: Distance-dependent filtering of background error covariance estimates in an ensemble Kalman filter, Mon. Weather Rev., 129, 2776-2790, 2001.

Hanea, R. G., Velders, G. J. M., and Heemink, A.: Data assimilation of ground-level ozone in Europe with a Kalman filter and chemistry transport model, J. Geophys. Res., 109, D10302, doi:10.1029/2003JD004283, 2004.

Houtekamer, P. L. and Mitchell, H. L.: Data assimilation using an ensemble Kalman filter technique, Mon. Weather Rev., 126, 796$811,1998$.

Houtekamer, P. L., Mitchell, H. L., Pellerin, G., et al.: Atmospheric data assimilation with an ensemble Kalman filter: Results with real observations, Mon. Weather Rev., 133(3), 604-620, 2005.

Jaffe, D., Anderson, T., Covert, D., et al.: Transport of Asian air pollution to North America, Geophys. Res. Lett., 26(6), 711714, doi:10.1029/1999GL900100, 1999.

Juckes, M. N. and Lawrence, B. N.: Data Assimilation for Reanalyses: potential gains from full use of post-analysis-time observa- 
tions, Tellus A, 58(2), 171-178, 2006.

Khattatov, B. V., Lamarque, J.-F., Lyjak, L. V., et al.: Assimilation of satellite observations of long-lived chemical species in global chemistry transport models, J. Geophys. Res., 105(D23), 29 13529 144, doi:10.1029/2000JD900466, 2000.

Lamarque, J.-F., Khattatov, B. V., Gille, J. C., and Brasseur, G. P.: Assimilation of Measurement of Air Pollution from space (MAPS) CO in a global three-dimensional model, J. Geophys. Res., 104(D21), 26 209-26218, doi:10.1029/1999JD900807, 1999.

Lamarque J.-F. and Gille, J. C.: Improving the modeling of error variance evolution in the assimilation of chemical species: Application to MOPITT data, Geophys. Res. Lett., 30(9), 1470, doi:10.1029/2003GL016994, 2003.

Lamarque, J.-F., Khattatov, B. V., and Gille, J. C.: Constraining tropospheric ozone column through data assimilation, J. Geophys. Res., 107(D22), 4651, doi:10.1029/2001JD001249, 2002.

Lamarque, J.-F., Khattatov, B. V.,Yudin, V., et al.: Application of a bias estimator for the improved assimilation of Measurements of Pollution in the Troposphere (MOPITT) carbon monoxide retrievals, J. Geophys. Res., 109, D16304, doi:10.1029/2003JD004466, 2004.

Lamarque J.-F., Kiehl, J. T., Hess, P. G., et al.: Response of a coupled chemistry climate model to changes in aerosol emissions: Global impact on the hydrological cycle and the tropospheric burdens of $\mathrm{OH}$, ozone, and NOx, Geophys. Res. Lett., 32, L16809, doi:10.1029/2005GL023419, 2005.

Lary, D. J.: Data assimilation: a powerful tool for atmospheric chemistry, Philos. Trans. R. Soc. Lond. Ser. A. Math Phys., 357(1763), 3445-3457, 1999.

Lawrence, M. G., Hov, Ø., Beekmann, M., et al.: The Chemical Weather, Environ. Chem., 2, 6-8, doi:10.1071/EN05014, 2005.

Levelt, P. F., Khattatov, B. V., Gille, J. C., et al.: Assimilation of MLS ozone measurements in the global three-dimensional chemistry transport model ROSE, Geophys. Res. Lett., 25(24), 44934496, doi:10.1029/1998GL900152, 1998.

Liang, Q., Jaeglé, L., Jaffe, D. A., et al.: Long-range transport of Asian pollution to the northeast Pacific: Seasonal variations and transport pathways of carbon monoxide, J. Geophys. Res., 109, D23S07, doi:10.1029/2003JD004402, 2004.

Logan, J. A., Prather, M. J., Wofsy, S. C., and McElroy, M. B.: Tropospheric chemistry: A global perspective, J. Geophys. Res., 86, 7210-7254, 1981.

Lorenc, A. C.: The potential of the ensemble Kalman . lter for NWP-a comparison with 4D-Var, Q. J. Roy. Meteor. Soc., 129, 3183-3203, 2003.

McLaughlin, D., O’Neill, A., Derber, J., and Kamachi, M.: Opportunities for enhanced collaboration within the data assimilation community, Q. J. Roy. Meteor. Soc., 131, 3683-3693, 2005.

Menard, R., Cohn, S. E., Chang, L.-P., and Lyster, P. M.: Assimilation of Stratospheric Chemical Tracer Observations Using a Kalman Filter, Part I: Formulation, Mon. Weather Rev., 128, 2654-2671, 2000.

Muller, J. F. and T. Stavrakou, T.: Inversion of CO and NOx emissions using the adjoint of the IMAGES model, Atmos. Chem. Phys., 5, 1157-1186, 2005,

http://www.atmos-chem-phys.net/5/1157/2005/.
Novelli, P. C., Masarie, K. A., Lang, P. M., et al.: Reanalysis of tropospheric CO trends: Effects of the 1997-1998 wildfires, J. Geophys. Res., 108(D15), 4464, doi:10.1029/2002JD003031, 2003.

Peters, W., Miller, J. B., Whitaker, J., et al.: An ensemble data assimilation system to estimate $\mathrm{CO}_{2}$ surface fluxes from atmospheric trace gas observations, J. Geophys. Res., 110, D24304, doi:10.1029/2005JD006157, 2005.

Pétron, G., Granier, C., Khattatov, B., et al:: Monthly CO surface sources inventory based on the 2000-2001 MOPITT satellite data, Geophys. Res. Lett., 31, L21107, doi:10.1029/2004GL020560, 2004.

Rabier, F.: Overview of global data assimilation developments in numerical weather-prediction centres, Q. J. Roy. Meteor. Soc., 131, 3215-3233, 2005.

Rasch, P. J., Coleman, D. B., Mahowald, N., et al.: Characteristics of atmospheric transport using three numerical formulations for atmospheric dynamics in a single GCM framework, J. Climate, 19(11), 2243-2266, 2006.

Rasch, P. J., Collins, W. D., and Eaton, B. E.: Understanding the Indian Ocean Experiment (INDOEX) aerosol distributions with an aerosol assimilation, J. Geophys. Res., 106(D7), 7337-7356, doi:10.1029/2000JD900508, 2001.

Rayner, P. J., Scholze, M., Knorr, W., et al.: Two decades of terrestrial carbon fluxes from a carbon cycle data assimilation system (CCDAS), Global Biogeochem. Cy., 19, GB2026, doi:10.1029/2004GB002254, 2005.

Sandu, A., Constantinescu, E. M., Liao, W., et al.: Ensemblebased data assimilation for atmospheric chemical transport models, Lect. Notes in Comp. Sci., 3515, 648-655, 2005.

Sekiyama, T. T. and Shibata, K.: Predictability of Total Ozone Using a Global Three-Dimensional Chemical Transport Model Coupled with the MRI/JMA98 GCM, Mon. Weather Rev. 133(8), 2262-2274, 2005.

Stajner, I., Riish øjgaard, L. P., and Rood, R.: The GEOS ozone data assimilation system: specification of error statistics, Q. J. Roy. Meteor. Soc., 127, 1069-1094, 2001.

Tippett, M. K., Anderson, J. L., Bishop, C. H., et al.: Ensemble square root filters, Mon. Weather Rev., 131, 1485-1490, 2003.

Van Loon, M., Builtjes, P. J. H., and Segers, A.: Data assimilation of ozone in the atmospheric transport chemistry model LOTOS, Env. Mod. Softw., 15, 603-609, 2000.

van der Werf, G. R., Randerson, J. T., Giglio, L., et al.: Interannual variability in biomass burning emissions from 1997 to 2004, Atmos. Chem. Phys., 6, 3423-3441, 2006,

http://www.atmos-chem-phys.net/6/3423/2006/.

Wang, K. Y., Lary, D. J., Shallcross, D. E., et al.: A review on the use of the adjoint method in four-dimensional atmosphericchemistry data assimilation, Q. J. Roy. Meteor. Soc., 127(576), 2181-2204, 2001.

Yienger, J. J., Galanter, M., Holloway, T. A., et al.: The episodic nature of air pollution transport from Asia to North America, J. Geophys. Res., 105(D22), 26931-26946, doi:10.1029/2000JD900309, 2000.

Yudin, V. A., Pétron, G., Lamarque, J.-F., et al.: Assimilation of the 2000-2001 CO MOPITT retrievals with optimized surface emissions, Geophys. Res. Lett., 31, L20105, doi:10.1029/2004GL021037, 2004. 